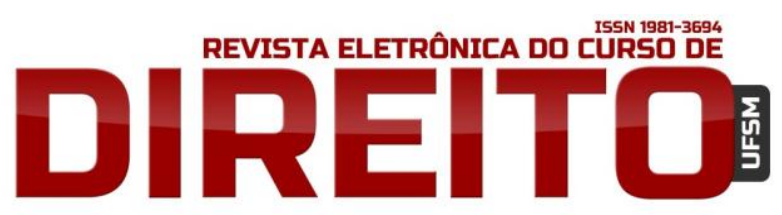

A REDUÇÃO DA MAIORIDADE PENAL E A VIOLAÇ̃̃O AO PRINCÍPIO DA IGUALDADE: A CONDIÇÃO PECULIAR DE PESSOA EM DESENVOLVIMENTO COMO ELEMENTO CONSTITUTIVO DA IDENTIDADE DO ADOLESCENTE

\title{
A REDUÇÃO DA MAIORIDADE PENAL E A VIOLAÇÃO AO PRINCÍPIO DA IGUALDADE: A CONDIÇÃO PECULIAR DE PESSOA EM DESENVOLVIMENTO COMO ELEMENTO CONSTITUTIVO DA IDENTIDADE DO ADOLESCENTE
}

\author{
THE REDUCTION OF THE AGE OF CRIMINAL RESPONSIBILITY AND THE \\ VIOLATION OF THE PRINCIPLE OF EQUALITY: THE PECULIAR CONDITION \\ OF THE INDIVIDUAL IN DEVELOPMENT AS A CONSTITUTIVE ELEMENT OF \\ TEENAGER IDENTITY
}

LUCAS GONÇALVES DA SILVA

Mestre e Doutor pela Pontifícia Universidade Católica de São Paulo (PUC/SP). Professor Adjunto de Graduação e Coordenador do Programa de Mestrado em Direito na Universidade Federal de Sergipe (UFS), Aracajú, Sergipe, Brasil.

lucasgs@uol.com.br

MARCELo SERRANo SOUZA

Mestrando em Direito pela Universidade Federal de Sergipe (UFS), Aracajú, Sergipe, Brasil.

celo_serrano@hotmail.com

\begin{abstract}
RESUMO
0 artigo analisa a redução da maioridade penal prevista na PEC n. 171/93 como violação ao princípio da igualdade. Um dos objetivos é demonstrar que a supressão de direitos fundamentais por deliberação majoritária que afeta núcleo essencial da Constituição não é compatível com o constitucionalismo. A redução da maioridade penal ignora elemento constitutivo da identidade do adolescente, qual seja a condição peculiar de pessoa em fase de desenvolvimento. 0 artigo pretende demonstrar que a aprovação da PEC $n$. $171 / 93$ simboliza um retrocesso a título de direitos fundamentais em um Estado Democrático de Direito. 0 presente trabalho adotou o método dedutivo e se utilizou da contribuição de doutrina e de jurisprudência pertinentes sobre o tema. Ao final, conclui-se que a aprovação da PEC n. 171/93 implica violação ao princípio da igualdade, pois a deliberação majoritária atinge direitos fundamentais ligados à identidade de uma minoria e, por consequência, a própria dignidade humana.
\end{abstract}

Palavras-chave: Condição Peculiar de Pessoa em Desenvolvimento; Direito Fundamental; Redução da Maioridade Penal; Violação ao Princípio da Igualdade.

\begin{abstract}
The research analyzes the reduction of the age of criminal responsibility in the Brazilian Proposed Constitutional Amendment n. 171/93 as a violation of the principle of equality. One of the goals is to demonstrate that the suppression of fundamental rights by majority vote that affects the essential core of the Constitution is not compatible with constitutionalism. Lowering the age of criminal responsibility ignores a constitutive element of teenager identity, which is the peculiar condition of the individual in development. The paper intends to demonstrate that the approval of PCA n. 171/93 symbolizes a setback regarding fundamental rights in a democratic state. This research adopted the deductive method and used literature and jurisprudence that are relevant on the subject. Finally, it concludes that the approval of PCA n. 171/93 implies a violation of the principle of equality, because majority deliberation affects fundamental rights linked to the identity of a minority and, consequently, the very human dignity.
\end{abstract}

Keywords: Peculiar condition of the individual in development; Fundamental right; Reduction of age of criminal responsibility; Violation of the principle of equality. 


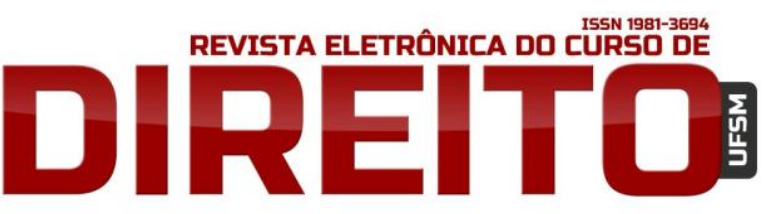

A REDUÇÃO DA MAIORIDADE PENAL E A VIOLAÇ̃̃O AO PRINCÍPIO DA IGUALDADE: A CONDIÇÃO PECULIAR DE PESSOA EM DESENVOLVIMENTO COMO ELEMENTO CONSTITUTIVO DA IDENTIDADE DO ADOLESCENTE

\section{SUMÁRIO}

INTRODUÇAO; 1 A LEGITIMAÇÃO DO DIREITO PENAL E AS FUNÇÕES DA PENA; 2 A IDENTIDADE COMO DIREITO FUNDAMENTAL DO ADOLESCENTE; 3 A DELIBERAÇÃO SOBRE A IDENTIDADE DO ADOLESCENTE: A REDUÇÃO DA MAIORIDADE PENAL COMO HIPÓTESE DE VIOLAÇÃO AO PRINCÍPIO DA IGUALDADE; CONCLUSÃO; REFERÊNCIAS.

\section{INTRODUÇÃO}

0 artigo tem como problema central a análise da redução da maioridade penal prevista na Proposta de Emenda Constitucional n. 171/93, como hipótese de violação ao princípio da igualdade. Avalia-se a supressão de direitos fundamentais por deliberação majoritária que afeta núcleo essencial da Constituição, qual seja, o elemento constitutivo da identidade do adolescente - a condição peculiar de pessoa em fase de desenvolvimento.

Para conferir neutralidade metodológica, o trabalho aborda alguns argumentos contrários à tese aqui defendida, a exemplo de: a) plena consciência dos adolescentes sobre seus atos e suas consequências; b) a existência de capacidade eleitoral ativa como fator de inserção dos adolescentes como sujeitos aptos a realizar escolhas importantes na sociedade.

Dentre os principais objetivos do artigo, cita-se a tentativa de se demonstrar que a aprovação da PEC n. 171/93 simboliza um retrocesso a título de direitos fundamentais em um Estado Democrático de Direito, em especial se analisados os argumentos que lhe dão suporte.

Ainda como objetivo, o artigo se desenvolveu a partir da premissa de que o direito fundamental à identidade do adolescente é corolário do princípio da dignidade da pessoa humana. A redução da maioridade penal afronta o princípio da igualdade por conferir o mesmo tratamento - ao longo do artigo, descrito como consequência da ideologia da defesa social - ao adulto e ao adolescente.

O presente trabalho adotou o método dedutivo e se utilizou de pesquisa doutrinária e jurisprudencial sobre a incidência do princípio da igualdade como norma de proteção aos direitos fundamentais do adolescente, sobretudo em consonância com os princípios da proteção integral e da condição peculiar de pessoa em desenvolvimento. Ademais, o estudo abordou dados estatísticos fornecidos por órgãos oficiais, seja para aferir o índice relativo de adolescentes que se envolvem em atos contra a vida, seja para comparar a idade penal brasileira com outros países de realidade social próxima. 
Em síntese, o artigo está estruturado em três tópicos. 0 primeiro apresenta a sistemática da legitimação do Direito Penal como ultima ratio para a solução de conflitos e a manutenção do pacto social, de maneira a tecer considerações críticas sobre a doutrina utilitarista e a ideologia da defesa social. Ao fim desse item, no tocante às funções da pena, argumenta-se que a PEC n. 171/93 se aproxima muito mais de um sentimento elitista de vingança direcionada a determinado grupo de pessoas do que de uma proposta com respaldo científico e com soluções efetivas ao problema da criminalidade.

O segundo tópico trabalha com a ideia de que o direito à identidade do adolescente é fundamental e decorre da própria dignidade da pessoa humana. Nesse ponto, defende-se que a construção da identidade do adolescente, a partir de fatores sociais, culturais e históricos, é pressuposto para o desenvolvimento de uma sociedade plural e democrática em que as diferenças não sejam causa de exclusão, mas sim de inclusão cidadã.

Em sequência, o terceiro tópico aborda a relação entre constitucionalismo e democracia, bem como identifica em que medida a deliberação da maioria sobre direitos fundamentais inerentes à identidade de uma minoria viola o princípio constitucional da igualdade.

O estudo concluiu que, sem considerar os critérios socioculturais e históricos da maioridade penal e do próprio conceito da adolescência, a aprovação da PEC n. 171/93 configura hipótese de violação ao princípio da igualdade, sobretudo porque, ainda que teoricamente majoritária, a deliberação atinge núcleo essencial da Constituição - a identidade do adolescente como corolário do princípio da dignidade da pessoa humana.

\section{A LEGITIMAÇÃO DO DIREITO PENAL E AS FUNÇÕES DA PENA}

O Direito Penal deve ser utilizado como ultima ratio na solução de conflitos sociais e, por isso, a pena - notadamente a privativa de liberdade - somente há de ser aplicada quando inexistente outra medida de controle sociopolítico menos gravosa aos direitos fundamentais do cidadão.

Segundo a doutrina de Roxin ${ }^{1}$, o Direito Penal dispõe sobre os requisitos de uma existência pacífica, livre e igualitária entre os indivíduos, sempre que outras soluções menos

${ }^{1}$ ROXIN, Claus. Estudos de Direito Penal. 2. ed. Tradução de Luís Greco. Rio de Janeiro: Renovar, 2008, p. 32-33. 
A REDUÇ̃̃O DA MAIORIDADE PENAL E A VIOLAČ̃̃ AO PRINCÍPIO DA IGUALDADE: A CONDICCÃO PECULIAR DE PESSOA EM DESENVOLVIMENTO COMO ELEMENTO CONSTITUTIVO DA IDENTIDADE DO ADOLESCENTE

LUCAS GONÇALVES DA SILVA MARCELO SERRANO SOUZA

onerosas aos direitos e às garantias individuais não sejam passíveis de adoção, a exemplo da proteção a bens jurídicos no âmbito do Direito Civil, do Direito Administrativo ou de outras medidas judiciais de caráter preventivo.

A legitimação do Direito Penal ${ }^{2}$ ocorre por meio da edição de normas - fonte primária -, em atenção à expressão máxima do princípio nullun crimen, nulla poena sine lege. Esse cenário exige a prévia existência de lei em sentido formal e material que defina condutas tipificadas como crime e as correspondentes sanções.

É fato público que, no dia 19 de agosto de 2015, a Câmara dos Deputados ${ }^{3}$ aprovou, em segundo turno, a Proposta de Emenda Constitucional n. 171/93, cujo ponto principal é a alteração do artigo 228 da Constituição Federal ${ }^{4}$, tudo para promover a redução da maioridade penal para a faixa etária dos 16 (dezesseis) anos.

Ao estudar a relação entre o princípio da igualdade - em especial os caracteres que constituem a identidade da criança e do adolescente - e a redução da maioridade penal, é preciso analisar a seletividade do Direito Penal.

Zaffaroni $^{5}$ adverte que, o caráter seletivo do Direito Penal está intrinsecamente relacionado a uma forma de contenção da criminalidade. Além disso, no transcurso da história, o poder punitivo do Estado procurou segregar determinados grupos de indivíduos, muitas vezes, com a adoção de tratamento que em nada correspondia à condição de pessoa titular de direitos e garantias. A punição alcançava seres humanos que estavam à margem do poder e, portanto, mais vulneráveis a todo o tipo de violência e de arbitrariedade. Por considerá-los inimigos da sociedade, o controle deveria recair sobre esses seres discriminados.

Diante desse cenário, ao menos na prática, o Direito Penal não confere igual proteção a todos os bens de interesse dos cidadãos, bem assim a lei penal não se apresenta igual para todos os indivíduos, independentemente da lesividade social e da gravidade dos crimes. 0 que se constata é a tentativa de contenção de grupos bem caracterizados ${ }^{6}$ e não a repressão de delitos de um modo geral.

\footnotetext{
${ }^{2}$ MIR PUIG, Santiago. Introduccion a las Bases del Derecho Penal. Buenos Aires: BdeF, 2003. p. 19.

${ }^{3}$ BRASIL. Câmara dos Deputados. Disponível em:

<http://www2.camara.leg.br/camaranoticias/noticias/DIREITO-E-JUSTICA/494248-CAMARA-APROVA-EM-2TURNO-REDUCAO-DA-MAIORIDADE-PENAL-EM-CRIMES-GRAVES.html>. Acesso em: 27 set. 2015.

${ }^{4}$ Artigo 228. São penalmente inimputáveis os menores de dezoito anos, sujeitos às normas da legislação especial.

5 ZAFFARONI, Eugenio Raúl. O inimigo no direito penal. Tradução de Sérgio Lamarão. 3. ed. Rio de Janeiro: Revan, 2007, p. 11.

${ }^{6}$ MUÑOZ CONDE, Francisco. Direito penal e controle social. Rio de Janeiro: Forense, 2005, p. 30-31.
} 
A REDUÇ̃̃O DA MAIORIDADE PENAL E A VIOLAČ̃̃ AO PRINCÍPIO DA IGUALDADE: A CONDICCÃO PECULIAR DE PESSOA EM DESENVOLVIMENTO COMO ELEMENTO CONSTITUTIVO DA IDENTIDADE DO ADOLESCENTE

LUCAS GONÇALVES DA SILVA MARCELO SERRANO SOUZA

A controvertida legitimação para a supressão de direitos fundamentais de adolescentes com a redução da maioridade penal se fundamenta, basicamente, em uma ideologia de defesa social. Ao tratar do tema, Baratta defende que a ideologia da defesa social surge em meio à revolução burguesa e a sua essência passa a integrar algumas ideias das ciências jurídicas e do senso comum. Segundo o referido doutrinador, “o conceito de defesa social corresponde a uma ideologia caracterizada por uma concepção abstrata e aistórica de sociedade, entendida como uma totalidade de valores e interesses"7.

Em síntese, a ideologia da defesa social estigmatiza o indivíduo que afronta o sistema de justiça criminal, de maneira a identificá-lo como elemento negativo que necessita de correção. Sob esse viés, a legitimidade do Estado para prevenir e punir a perturbação à ordem e à convivência social decorre do pacto social.

Atualmente, apesar de estatisticamente desconstruída inclusive pelo Estado brasileiro ${ }^{8}$, a tese de que os adolescentes infratores são responsáveis pela maioria dos ilícitos penais cometidos com grau elevado de violência é bandeira de defesa de diversos veículos de comunicação que tratam o sofrimento humano como espetáculo. Ao que parece, trata-se de uma espécie de critério seletivo para um grupo determinado sob a promessa inexequível de redução da criminalidade.

De acordo com Foucault ${ }^{9}$, ao infringir a lei penal, o indivíduo é contraposto a todo o corpo social que, a partir de então, incorpora uma espécie de legitimidade para levar a efeito uma punição contra aquele que atentou contra a paz social. Trata-se de uma luta desigual, isto é, de um lado, o infrator e, agora, inimigo comum da sociedade, e, de outro, todo o poder institucionalizado por meio de órgãos, em tese, bem estruturados para fazer valer a imperatividade da norma penal.

Ferrajoli ${ }^{10}$ menciona a existência de doutrinas utilitaristas que justificam a pena como sendo um meio de se evitar futuros delitos. Em outras palavras, a pena teria um caráter de a) prevenção geral, pois estabelece a finalidade preventiva aos cidadãos em geral; b) prevenção

\footnotetext{
${ }^{7}$ BARATTA, Alessandro. Criminologia crítica e crítica do direito penal: introdução à sociologia do direito penal. Rio de Janeiro: Revan; ICC, 2002, p. 47.

${ }^{8}$ Segundo o Ministério da Justiça, o percentual de adolescentes entre 16 e 18 anos que cometem atos infracionais é de $0,9 \%$ em relação ao total de crimes cometidos no Brasil, e de apenas 0,5\% em relação ao total de crimes de homicídio. Disponível em: <http://www.brasil.gov.br/cidadania-ejustica/2015/06/menores-cometem-0-9-dos-crimes-no-brasil>. Acesso em: 28 set. 2015.

${ }_{9}$ FOUCAULT, Michel. Vigiar e punir: nascimento da prisão. 39 ed. Rio de Janeiro: Editora Vozes, 2011, p. 86.

${ }^{10}$ FERRAJOLI, Luigi. Direito e Razão: teoria do garantismo penal. São Paulo: Editora Revista dos Tribunais, 2002, p. 204.
} 
A REDUÇ̃̃O DA MAIORIDADE PENAL E A VIOLAČ̃̃ AO PRINCÍPIO DA IGUALDADE: A CONDICCÃO PECULIAR DE PESSOA EM DESENVOLVIMENTO COMO ELEMENTO CONSTITUTIVO DA IDENTIDADE DO ADOLESCENTE

LUCAS GONÇALVES DA SILVA MARCELO SERRANO SOUZA

especial, porquanto sua finalidade é identificar o autor do delito e promover sua correção; e c) retributiva, considerando que a aplicação da pena se aproxima e muito da imposição de um castigo, de uma retribuição em razão da infração à lei penal.

O Direito Penal surge mais como uma negação da vingança do que uma evolução histórica da pena privativa de liberdade ${ }^{11}$. A pena não se justifica pelo sentimento de vingança, mas sim, para impedir atos calcados em justiça privada, já abolida há muito tempo. Por isso, a pena é um meio de combate à vingança.

Em contrariedade aos direitos e garantias fundamentais conquistados no decorrer da história $^{12}$, a Proposta de Emenda à Constituição n. 171/93 não apresenta uma solução concreta e comprovada empiricamente para reduzir a quantidade de atos infracionais protagonizada por adolescentes, mas pode servir como mais um instrumento altamente seletivo em relação a grupos que já se encontram em situação de vulnerabilidade social.

\section{A IDENTIDADE COMO DIREITO FUNDAMENTAL DA CRIANÇA E DO ADOLESCENTE}

A identidade é corolário do próprio princípio da dignidade da pessoa humana, previsto no artigo $1^{\circ}$, inciso III, da Constituição Federal/88. A identidade do ser humano resulta de sua percepção autoconsciente como característica imanente que o torna único e distinto em relação

\footnotetext{
${ }^{11}$ LOPES JR, Aury. Direito Processual Penal. 9. ed. rev. e atual. São Paulo: Saraiva, 2012, p. 60.

${ }^{12}$ Segundo os marcos de idade penal na história jurídica brasileira, a ideia de maioridade penal apresentou variação de acordo com fatores sociais, culturais e históricos. Em tempos em que apenas havia a condição de criança e a de adulto, para as Ordenações Filipinas, a responsabilidade penal plena era atingida ao se completar 7 (sete) anos de idade, com isenção da pena de morte até os 17 (dezessete) anos de idade. Por sua vez, o Código Penal do Império (1830) previa a imputabilidade relativa entre 7 (sete) e 14 (quatorze) anos, de modo que, a partir desse último marco etário, estabelecia-se a responsabilidade penal plena. 0 Código Penal Republicano (1889) manteve a responsabilidade penal plena aos 14 (quatorze) anos de idade, mas elevou para 9 (nove) anos de idade o marco inicial para a imputabilidade relativa. A partir do momento em que a adolescência é inserida como fase de desenvolvimento da pessoa humana, tem-se o Código de Menores de 1927 (Código Mello Matos), para o qual a imputabilidade relativa se iniciava aos 14 (quatorze) anos de idade e a responsabilidade penal plena aos 18 (dezoito) anos de idade. 0 Código Penal de 1940 fixou a responsabilidade penal plena aos 18 (dezoito) anos de idade e a Lei n. 7.209/84 (Reforma do Código Penal) tornou esse critério objetivo. Por último, em consonância com o texto constitucional de 1988, o Estatuto da Criança e do Adolescente estabeleceu a responsabilidade penal diferenciada aos indivíduos entre 12 (doze) anos completos e 18 (dezoito) anos incompletos. (SPOSATO, Karyna Batista. Direito Penal de Adolescentes: elementos para uma teoria garantista. São Paulo: Saraiva, 2013, p. 160 161).
} 
A REDUÇ̃̃O DA MAIORIDADE PENAL E A VIOLAČ̃̃ AO PRINCÍPIO DA IGUALDADE: A CONDICCÃO PECULIAR DE PESSOA EM DESENVOLVIMENTO COMO ELEMENTO CONSTITUTIVO DA IDENTIDADE DO ADOLESCENTE

LUCAS GONÇALVES DA SILVA MARCELO SERRANO SOUZA

a outro indivíduo. A visão moderna de identidade humana trabalha com a ideia de respeito às diferenças sociais e culturais presentes em um Estado Democrático de Direito.

Em estudo sobre o tema, o professor Martinazzo sublinha a importância da convivência social para a construção da identidade como verdadeira conquista da humanidade. E, mais, afirma que os traços que constituem a identidade do ser humano são capazes de, ao mesmo tempo, promover o resgate das semelhanças e a valorização das diferenças do indivíduo, litteris:

O homem não nasce pronto, aprende no e com o mundo, influenciado que é pela cultura, religião, crenças e outras formas culturais. Nós não nascemos humanos, nós nos tornamos humanos na convivência com os outros; a nossa identidade humana, portanto, é uma conquista a ser perseguida. Aprendemos a superar os obstáculos, a processar os conceitos e a construir as pontes que nos possibilitam compreender o mundo e a nós mesmos. Contemplar a identidade humana de cada um significa, portanto, resgatar aquilo que o faz semelhante e, ao mesmo tempo, diferente dos demais ${ }^{13}$.

A identidade, portanto, dignifica a existência humana. Considerando o direito constitucional como espécie de direito subjetivo que pode ser invocado pelo seu beneficiário a fim de tutelar bem jurídico socialmente relevante, tem-se que:

Direito é, também, em uma terceira acepção, a possibilidade que o beneficiário de uma norma tem de fazê-la atuar em seu favor, inclusive por meio de recurso à coação estatal. Normas jurídicas e, ipso facto, normas constitucionais tutelam bens jurídicos socialmente relevantes e interesses individuais. Um direito subjetivo constitucional confere a seu titular a faculdade de invocar a norma da Constituição para assegurar o desfrute da situação jurídica nela contemplada ${ }^{14}$.

Como se sabe, os direitos fundamentais são classificados em direitos de defesa e direitos de prestação. O direito fundamental à identidade da criança e do adolescente, sobretudo porque vinculado ao princípio da dignidade da pessoa humana, é classificado como direito de defesa e, por isso, reclama uma abstenção do poder estatal e dos particulares a fim de assegurar sua aplicação imediata, nos termos do artigo $5^{\circ}$, § $1^{\circ}$, da Constituição Federal.

Nesse ponto, Sarlet destaca que a aplicabilidade imediata e a plena eficácia dos direitos fundamentais de defesa encontram amparo "na circunstância de que as normas que os

\footnotetext{
${ }^{13}$ MARTINAZZO, Celso José. Identidade Humana. Contexto \& Educação. Ano 25, n. 84, jul/dez 2010, p. 35.

${ }^{14}$ BARROSO, Luís Roberto. Curso de Direito Constitucional Contemporâneo: os conceitos fundamentais e a construção do novo modelo. 5. ed. São Paulo: Saraiva, 2015, p. 74.
} 
A REDUÇ̃̃O DA MAIORIDADE PENAL E A VIOLAČ̃̃ AO PRINCÍPIO DA IGUALDADE: A CONDICCÃO PECULIAR DE PESSOA EM DESENVOLVIMENTO COMO ELEMENTO CONSTITUTIVO DA IDENTIDADE DO ADOLESCENTE

LUCAS GONÇALVES DA SILVA MARCELO SERRANO SOUZA

consagram receberam do Constituinte, em regra, a suficiente normatividade e independem de concretização legislativa” ${ }^{15}$.

A propósito, ao reconhecer repercussão geral à questão constitucional, o Supremo Tribunal Federal firmou entendimento no sentido de que a identidade "está diretamente ligada à dignidade da pessoa humana e a direitos de personalidade"16.

No tocante à responsabilidade em relação à criança e ao adolescente, o artigo 227 da Constituição Federal $^{17}$ estabelece a responsabilidade comum e concorrente da família, da sociedade e do Estado na proteção e na observância dos direitos e garantias fundamentais. Quanto maior o respeito aos direitos fundamentais das crianças e dos adolescentes, maior será a realização do princípio da democracia em prol da construção de uma identidade e de um projeto de vida para esse novo sujeito titular de direitos.

Em reprodução ao direito fundamental previsto constitucionalmente, o Estatuto da Criança e do Adolescente estabelece como dever da família, da sociedade e do Estado, em grau de absoluta prioridade, “a efetivação dos direitos referentes à vida, à saúde, à alimentação, à educação, [...] à dignidade, ao respeito, à liberdade e à convivência familiar e comunitária" ${ }^{18}$.

0 rol de garantias previsto no artigo $4^{\circ}$ do Estatuto da Criança e do Adolescente tem como finalidade atender as novas exigências e demandas da sociedade, de modo a identificar os novos sujeitos titulares de direito e, por consequência, estabelecer uma série de garantias diferenciadas, bem como proteger a criança e o adolescente do preconceito, da violência e da negligência, seja por parte da família, da sociedade ou do Estado ${ }^{19}$.

Já 0 artigo $6^{\circ}$ do Estatuto da Criança e do Adolescente dispõe que devem ser considerados "os fins sociais a que ela se dirige, as exigências do bem comum, os direitos e

\footnotetext{
15 SARLET. Ingo Wolfgang. A Eficácia dos Direitos Fundamentais: uma teoria geral dos direitos fundamentais na perspectiva constitucional. 12. ed. rev. atual. e ampl. Porto Alegre: Livraria do Advogado, 2015, p. 283.

${ }^{16}$ BRASIL. Supremo Tribunal Federal. Recurso Extraordinário 845.779 RG, Rel. Min. ROBERTO BARROSO, julgado em 13.11.2014, PROCESSO ELETRÔNICO DJe-045 DIVULG 09-03-2015 PUBLIC 10-03-2015. In: Site do Supremo Tribunal Federal. Disponível em: <http://www.stf.jus.br/portal/jurisprudencia/listarJurisprudencia.asp?s1=\%28direito+fundamental+identi dade\%29\&base=baseRepercussao\&url=http://tinyurl.com/ovwgc5h>. Acesso em 28 set. 2015.

${ }_{17}$ BRASIL. Constituição da República Federativa do Brasil de 1988. Diário Oficial da República Federativa do Brasil, Brasília, DF, 5 out. 1988. Disponível em: <http://www.planalto.gov.br/ccivil_03/Constituicao/Constituiçao.htm>. Acesso em: 25 set. 2015.

${ }^{18}$ BRASIL. Lei $n^{\circ} 8.069$ de 13 de julho de 1990. Dispõe sobre o Estatuto da Criança e do Adolescente e dá outras providências. Diário Oficial da República Federativa do Brasil, Brasília, DF, 16 jul. 1990. Disponível em: <http://www.planalto.gov.br/ccivil_03/Leis/L6938.htm>. Acesso em: 25 set. 2015.

19 RAMIDOFF, Mário Luiz. Lições de Direito da Criança e do Adolescente: ato infracional e medidas socioeducativas. Curitiba: Juruá, 2011, p. 45.
} 
A REDUÇ̃̃O DA MAIORIDADE PENAL E A VIOLAČ̃̃ AO PRINCÍPIO DA IGUALDADE: A CONDICCÃO PECULIAR DE PESSOA EM DESENVOLVIMENTO COMO ELEMENTO CONSTITUTIVO DA IDENTIDADE DO ADOLESCENTE

LUCAS GONÇALVES DA SILVA MARCELO SERRANO SOUZA

deveres individuais e coletivos, e a condição peculiar da criança e do adolescente como pessoas em desenvolvimento"20.

Ainda que, o adolescente venha a cometer ato infracional, eventual imposição de medida socioeducativa há de permitir, não só a (re)construção de sua identidade, mas também a inclusão na sociedade, nos termos do Sistema Nacional de Atendimento Socioeducativo - SINASE, litteris:

As ações socioeducativas devem exercer influência sobre a vida do adolescente, contribuindo para a construção de sua identidade, de modo a favorecer a elaboração de um projeto de vida, o seu pertencimento social e o respeito às diversidades (cultural, étnico-racial, de gênero e orientação sexual), possibilitando que assuma um papel inclusivo na dinâmica social e comunitária. Para tanto, é vital a criação de acontecimentos que fomentem o desenvolvimento da autonomia, da solidariedade e de competências pessoais relacionais, cognitivas e produtivas ${ }^{21}$.

No âmbito internacional, a Convenção sobre os Direitos da Criança ${ }^{22}$, editada em 1989 pela Assembleia Geral das Nações Unidas e ratificada pelo Brasil em 1990, prevê, não só o direito à identidade da criança, mas também o dever de restabelecê-lo em caso de ilegal privação de algum elemento constitutivo de sua identidade.

Dessa forma, os Estados signatários devem observar, além da condição isolada de criança, a sua condição peculiar em fase de desenvolvimento, a exemplo das suas características pessoais, sociais, culturais, étnicas e religiosas, elementos básicos que constituem a identidade do indivíduo.

\footnotetext{
${ }^{20}$ BRASIL. Lei $n^{\circ} 8.069$ de 13 de julho de 1990. Dispõe sobre o Estatuto da Criança e do Adolescente e dá outras providências. Diário Oficial da República Federativa do Brasil, Brasília, DF, 16 jul. 1990. Disponível em: <http://www.planalto.gov.br/ccivil_03/Leis/L6938.htm>. Acesso em: 25 set. 2015.

${ }_{21}$ BRASIL. Presidência da República. Secretaria Especial dos Direitos Humanos. Conselho Nacional dos Direitos da Criança e do Adolescente. Sistema Nacional De Atendimento Socioeducativo SINASE/Secretaria Especial dos Direitos Humanos. Brasília - DF: CONANDA, 2006, p. 52. Disponível em: <http://www.conselhodacrianca.al.gov.br/sala-de-imprensa/publicacoes/sinase.pdf>. Acesso em 25 set. 2015.

${ }^{22}$ Artigo $8^{\circ}$ :

1. Os Estados-partes se comprometem a respeitar o direito da criança, de preservar sua identidade, inclusive a nacionalidade, o nome e as relações familiares, de acordo com a lei, sem interferências ilícitas.

2. No caso de uma criança se vir ilegalmente privada de algum ou de todos os elementos constitutivos de sua identidade, os Estados partes fornecer-lhe-ão assistência e proteção apropriadas, de modo que sua identidade seja prontamente restabelecida.
} 


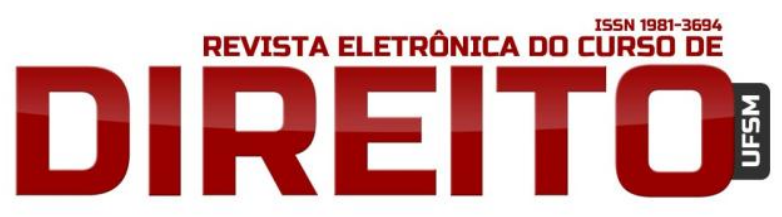

A REDUÇÃO DA MAIORIDADE PENAL E A VIOLAÇ̃̃O AO PRINCÍPIO DA IGUALDADE: A CONDIÇÃO PECULIAR DE PESSOA EM DESENVOLVIMENTO COMO ELEMENTO CONSTITUTIVO DA IDENTIDADE DO ADOLESCENTE

LUCAS GONÇALVES DA SILVA MARCELO SERRANO SOUZA

Considerando que as crianças e os adolescentes são seres humanos que se encontram em fase de formação física, moral e intelectual é imperioso, que o Estado forneça meios idôneos para assegurar a proteção especial prevista na Constituição Federal de 1988.

A condição peculiar de pessoa em fase de desenvolvimento inerente à criança e ao adolescente se baseia principalmente na necessidade de construção cultural da identidade e na situação de vulnerabilidade social, razão pela qual a proteção específica conferida a esses sujeitos titulares de direitos deve ser garantida por medidas eficientes de participação em decisões estatais, em especial no tocante às políticas públicas.

Um dos exemplos experimentados no território brasileiro foi financiado com recursos do Banco Nacional do Desenvolvimento - BNDES. Trata-se do Programa de Apoio a Crianças e Jovens em Situação de Risco Social, na linha denominada "Redes Locais de Atenção à Criança e ao Adolescente" criada em 1999. Um dos objetivos do citado programa é promover "a participação da sociedade civil na política de atendimento, de forma ampliada e a qualquer tempo"23.

O citado programa desenvolveu, em alguns municípios do Brasil, medidas concretas de apoio para a concretização das garantias asseguradas pela Lei Federal n. 8.069/90 às crianças e aos adolescentes. 0 direcionamento dos recursos públicos aos municípios se deve ao fato de que o primeiro atendimento da criança ou do adolescente em situação de risco social é realizado a nível local, o que corrobora a ideia de que quanto maior a participação da sociedade na formação e na execução das políticas públicas maior é o grau de democracia ali existente.

Além de constituir direito fundamental vinculado à dignidade da pessoa humana, a construção da identidade do adolescente - ser humano em estágio de formação - é apenas o ponto de partida para o desenvolvimento de uma sociedade plural e democrática em que as diferenças não são causa de exclusão, mas sim de inclusão cidadã.

\section{A DELIBERAÇÃO SOBRE A IDENTIDADE DO ADOLESCENTE: A REDUÇÃO DA MAIORIDADE PENAL COMO HIPÓTESE DE VIOLAÇÃO AO PRINCÍPIO DA IGUALDADE}

\footnotetext{
${ }^{23}$ BARBOSA, Ana Christina Moreno Maia; COSTA, Ana Cristina Rodrigues da. Políticas de Atenção Integral redes locais de atenção à criança e ao adolescente. In: AZEREDO, Beatriz; DUNCAN, Pedro Gomes (Orgs.). A experiência da área de desenvolvimento social no período 1996-2002. Rio de Janeiro: BNDES, 2002, p. 107-116.
} 
A REDUÇ̃̃O DA MAIORIDADE PENAL E A VIOLAČ̃̃ AO PRINCÍPIO DA IGUALDADE: A CONDICCÃO PECULIAR DE PESSOA EM DESENVOLVIMENTO COMO ELEMENTO CONSTITUTIVO DA IDENTIDADE DO ADOLESCENTE

LUCAS GONÇALVES DA SILVA MARCELO SERRANO SOUZA

A definição de democracia não se limita a um mero conceito abstrato e imutável, mas é um processo constante de construção de identidade e de manutenção dos direitos fundamentais conquistados no decorrer da história ${ }^{24}$. Portanto, à luz do disposto no artigo $1^{\circ}$, parágrafo único, da Constituição Federal/88, trata-se de um instrumento legítimo de realização de valores essenciais por meio da máxima de que "todo o poder emana do povo que o exerce por meio de representantes eleitos ou diretamente, nos termos desta Constituição"25.

Silva ${ }^{26}$ entende que a adoção do princípio majoritário pelo Brasil o torna um Estado Democrático, ao passo que a incidência do princípio da supremacia da Constituição e a busca pela efetividade dos direitos fundamentais definem o Brasil como um Estado de Direito.

O constitucionalismo e a democracia, embora conceitualmente próximos, não se confundem. Enquanto constitucionalismo simboliza limitação de poder e supremacia da lei, a democracia representa soberania popular e governo da maioria. Para Barroso, entre constitucionalismo e democracia podem surgir pontos de tensão: “a vontade da maioria pode ter de estancar diante de determinados conteúdos materiais, orgânicos ou processuais da Constituição"27.

E é nesse momento que surge a possibilidade de reforma do texto constitucional. Silva menciona três funções da reforma constitucional, de modo que a principal delas merece destaque neste artigo. Trata-se da função de "instrumento de adequação entre a realidade jurídica e a realidade política" ${ }^{28}$. A normatividade constitucional não acompanha em tempo real a dinâmica dos fatos em sociedade, razão pela qual esse ajuste é necessário até mesmo para que a Constituição seja duradoura e simbolize uma ordem constitucional democrática.

o Poder Constituinte Derivado é eminentemente jurídico e se materializa com o exercício de uma competência reformadora, ao passo que o Poder Constituinte Originário representa uma ruptura com o modelo anterior e se materializa como um poder de fato ${ }^{29}$.

\footnotetext{
${ }^{24}$ SILVA, José Afonso da. Curso de direito constitucional positivo. 34. ed. São Paulo: Malheiros, 2011. p. 125-126.

${ }^{25}$ BRASIL. Constituição da República Federativa do Brasil de 1988. Diário Oficial da República Federativa do Brasil, Brasília: 5 out. 1988. Disponível em: <http://www.planalto.gov.br/ccivil_03/Constituicao/ Constituiçao.htm>. Acesso em: 25 set. 2015.

${ }^{26}$ SILVA, José Afonso da. Curso de direito constitucional positivo. 34. ed. São Paulo: Malheiros, 2011, p. 119-120.

${ }^{27}$ BARROSO, Luís Roberto. Curso de Direito Constitucional Contemporâneo: os conceitos fundamentais e a construção do novo modelo. 5. ed. São Paulo: Saraiva, 2015, p. 112-113.

${ }_{28}$ SILVA, José Afonso da. Poder Constituinte e Poder Popular. 1. ed. 3. tir. São Paulo: Malheiros, 2007, p. 246.

${ }^{29}$ ARAÚJO, Luiz Alberto David; NUNES JUNIOR, Vidal Serrano. Curso de Direito Constitucional. 14. ed. São Paulo: Saraiva, 2010, p. 31.
} 
A REDUÇ̃̃O DA MAIORIDADE PENAL E A VIOLAČ̃̃ AO PRINCÍPIO DA IGUALDADE: A CONDICCÃO PECULIAR DE PESSOA EM DESENVOLVIMENTO COMO ELEMENTO CONSTITUTIVO DA IDENTIDADE DO ADOLESCENTE

LUCAS GONÇALVES DA SILVA MARCELO SERRANO SOUZA

A fim de justificar a legitimidade das reformas constitucionais, alguns limites são impostos ao Poder Constituinte Derivado, a exemplo dos limites materiais, formais, circunstanciais, temporais e implícitos. Em relação aos limites materiais, tem-se que o artigo 60, $\S 4^{\circ}$, da Constituição de 1988 exclui a possibilidade de emendas que tratem da abolição da forma federativa de Estado, do voto direto, secreto, universal e periódico, da separação de poderes e dos direitos e garantias individuais.

As cláusulas pétreas não estão inseridas no texto constitucional apenas para impedir a "desconstituição" da Constituição, mas cumprem a finalidade de inibir a simples tentativa de abolição do projeto constitucional original, sobretudo ante a situação de "sedução e de apelos próprios de certo momento político" ${ }^{30}$ como fator de desestruturação de um projeto duradouro.

Por essas razões, a proteção e a promoção dos direitos fundamentais, ainda que não seja essa a vontade das maiorias políticas do momento, constitui pressuposto para o efetivo funcionamento do constitucionalismo democrático. A intervenção do Judiciário, ao corrigir uma omissão legislativa ou declarar uma lei inconstitucional, significa a realização e não o desvirtuamento da democracia ${ }^{31}$. E a aprovação da Proposta de Emenda à Constituição n. 171/93 configura hipótese de violação a um conteúdo material por uma deliberação de maioria, em tese, democrática.

Ferrajoli $^{32}$ sustenta que, a Declaração de Direitos de 1789 inovou quando conferiu ao princípio da igualdade o status de norma jurídica. Desde então, segundo o autor, a igualdade não seria um simples fato, mas sim um valor, sobretudo porque se reconhece que os seres humanos são diferentes e a intenção é justamente impedir que essas diferenças constituam fatores de desigualdade.

A igualdade jurídica é precisamente a igualdade em direitos. É a relação que une uma classe de sujeitos à titularidade de certos direitos, que podem ser universais ou fundamentais, se garantidos a todos e em igual medida. Diferenças, sejam naturais ou culturais, são os traços específicos das pessoas que as tornam individualizadas e titulares de direitos fundamentais, razão pela qual concorrem para a formação da identidade da pessoa.

\footnotetext{
${ }^{30}$ MENDES, Gilmar Ferreira. COELHO, Inocêncio Mártires. BRANCO, Paulo Gustavo Gonet. Curso de direito constitucional. 3. ed. rev. atual. São Paulo: Saraiva, 2008, p. 218.

31 BINENBOJM, Gustavo. A nova jurisdição constitucional brasileira: legitimidade democrática e instrumentos de realização. 2. ed. Rio de Janeiro: Forense, 2004, p. 246.

32 FERRAJOLI, Luigi. Derechos y garantias: la ley del más débil. Madrid: Editorial Trotta, 2001, p. 80-81.
} 
A REDUÇ̃̃O DA MAIORIDADE PENAL E A VIOLAČ̃̃ AO PRINCÍPIO DA IGUALDADE: A CONDICCÃO PECULIAR DE PESSOA EM DESENVOLVIMENTO COMO ELEMENTO CONSTITUTIVO DA IDENTIDADE DO ADOLESCENTE

LUCAS GONÇALVES DA SILVA MARCELO SERRANO SOUZA

Já as desigualdades, tanto econômicas como sociais, refletem a disparidade entre sujeitos, geralmente em razão de direitos patrimoniais e de posições de poder, cenário que contribui para a formação das esferas jurídicas da pessoa.

Em ambos os casos, a igualdade está conectada aos direitos fundamentais: aos de liberdade, enquanto direito ao respeito das diferenças; aos sociais, enquanto direito à redução das desigualdades. As discriminações são as desigualdades antijurídicas, situação em que o princípio da igualdade é violado por uma situação fática de desrespeito a um direito fundamental. É um tratamento desigual em relação a diferenças tuteladas pelo princípio da igualdade. 0 objetivo de qualquer política democrática de direito é remover as discriminações por meio de garantias idôneas ${ }^{33}$.

Conclui Ferrajoli que nenhuma maioria pode decidir em matéria de direitos fundamentais pelos demais indivíduos, sobretudo quando a minoria tem interesses ligados à sua identidade. No presente artigo, defende-se que, ainda que a aprovação da PEC n. 171/93 tenha ocorrido com ampla aceitação popular, a faixa etária e a condição peculiar de pessoa em desenvolvimento do adolescente são elementos constitutivos de identidade e, por isso, a inviabilidade de se levar a efeito uma deliberação que reduz direitos fundamentais.

A crise simultânea do estado de direito, do estado social e do estado nacional impõe uma reflexão sobre as sedes do constitucionalismo, vale dizer, sobre a fonte das garantias rígidas impostas constitucionalmente a todos os poderes em relação à defesa dos direitos fundamentais. Ferrajoli ${ }^{34}$ demonstra preocupação com a possibilidade de redução de direitos fundamentais não só pelo legislador ordinário, mas pelo legislador constitucional de revisão, o que se denomina de debilidade constitucional a título de teoria dos direitos fundamentais.

A propósito, nos autos do Habeas Corpus n. 85.687/RS, o Ministro Gilmar Mendes proferiu voto no sentido de que, apesar da ausência expressa de um núcleo essencial, “é certo que tal princípio decorre do próprio modelo garantístico utilizado pelo constituinte" e "a não admissão de um limite ao afazer legislativo tornaria inócua qualquer proteção fundamental”35.

Em estudo realizado pelo Instituto de Psicologia da Universidade de Brasília, verificou-se que o conceito de adolescência passa por questões sociais, culturais e históricas.

\footnotetext{
${ }^{33}$ FERRAJOLI, Luigi. Derechos y garantias: la ley del más débil. Madrid: Editorial Trotta, 2001, p. 83.

${ }^{34}$ Ibid. p. 114.

35 BRASIL. Supremo Tribunal Federal. Habeas Corpus n. 85.687/RS, Rel. Min. Carlos Velloso, Segunda Turma, julgado em 17.05.2005. In: Site do Supremo Tribunal Federal. Disponível em: <http://redir.stf.jus.br/paginadorpub/paginador.jsp?docTP=AC\&doclD=354246>. Acesso em: 28 set. 2015.
} 
A REDUÇ̃̃O DA MAIORIDADE PENAL E A VIOLAČ̃̃ AO PRINCÍPIO DA IGUALDADE: A CONDICCÃO PECULIAR DE PESSOA EM DESENVOLVIMENTO COMO ELEMENTO CONSTITUTIVO DA IDENTIDADE DO ADOLESCENTE

LUCAS GONÇALVES DA SILVA MARCELO SERRANO SOUZA

Um dos principais argumentos utilizados em defesa da redução da maioridade penal é o de que os adolescentes já possuem plena consciência dos seus atos e devem por eles responder, o que denota a aplicação dos critérios cronológico e biológico, contudo sem referência aos critérios sociais, educacionais e culturais ${ }^{36}$.

Ainda sobre os argumentos favoráveis à redução da maioridade penal, há de se ressaltar que a capacidade eleitoral ativa do adolescente - faculdade de escolher representantes - não se confunde com a capacidade de responder penalmente perante a sociedade e o Estado. Salientese, por oportuno, que o adolescente não possui capacidade eleitoral passiva, ou seja, capacidade para registrar candidatura e obter a eleição para exercício de mandato ou de cargo político, o que somente ocorre aos 18 (dezoito) anos de idade.

Em relação aos outros países, é possível aferir que o Brasil acompanha a tendência mundial em torno da responsabilidade penal de adultos aos 18 (dezoito) anos de idade. Conforme dados do Fundo das Nações Unidas para a Infância - UNICEF -, apenas a título de nota, tantos outros países da América Latina adotam a idade penal aos 18 (dezoito) anos, a exemplo da Argentina, do Uruguai, do Paraguai, da Colômbia, do Chile, do Peru, do Equador, da Venezuela, do México e de outros mais ${ }^{37}$. Portanto, a aprovação da PEC 171/93 pelo Senado Federal pode representar um desalinhamento do Brasil com seus países vizinhos.

A propósito, considerando a relevância da construção da identidade do adolescente em um ambiente que se diz democrático, o representante do UNICEF no Brasil emitiu nota pública, em março de 2015, contrária à redução da maioridade penal. Segundo dados publicados na referida notícia, dos 21 milhões de adolescentes no Brasil, apenas 0,01\% deles teve envolvimento com algum ato contra a vida. E, mais, aponta que o sistema de responsabilidade juvenil brasileiro é altamente seletivo, de modo que "em sua grande maioria, são meninos negros, pobres, que vivem nas periferias das grandes cidades"38.

No caso em estudo, não há que se tratar de forma igual o adulto que comete crime e o adolescente que pratica ato infracional, sobretudo em razão do diferenciado grau de

\footnotetext{
${ }^{36}$ ALVES, Cândida et al . Adolescência e maioridade penal: reflexões a partir da psicologia e do direito. Psicol. Polít., São Paulo, v. 9, n. 17, p. 67-83, jun. 2009. Disponível em <http://pepsic. bvsalud.org/scielo.php?script=sci_arttext\&pid=S1519-

549X2009000100005\&lng=pt\&nrm=iso>. Acesso em: 18 ago. 2016.

37 BRASIL. Ministério Público do Estado do Paraná. Idade Penal: tabela comparativa. Disponível em: <http://http://www.crianca.mppr.mp.br/modules/conteudo/conteudo.php?conteudo=323>. Acesso em: 18 ago. 2016.

38 BRASIL. UNICEF. UNICEF é contra a redução da maioridade penal. Disponível em: <http://http://www.unicef.org/brazil/pt/media_29163.htm>. Acesso em: 18 ago. 2016.
} 
A REDUÇ̃̃O DA MAIORIDADE PENAL E A VIOLAČ̃̃ AO PRINCÍPIO DA IGUALDADE: A CONDICCÃO PECULIAR DE PESSOA EM DESENVOLVIMENTO COMO ELEMENTO CONSTITUTIVO DA IDENTIDADE DO ADOLESCENTE

LUCAS GONÇALVES DA SILVA MARCELO SERRANO SOUZA

imputabilidade penal, isto é, a capacidade que o agente tem de entender a natureza ilícita da conduta e de se portar diante desse conhecimento. Esse é o fundamento lógico que justifica o tratamento penal distinto conferido aos adultos e aos adolescentes.

0 critério discriminatório guarda harmonia com o artigo 228 da Constituição Federal, segundo o qual "são penalmente inimputáveis os menores de dezoito anos, sujeitos às normas da legislação especial”39, além da previsão de princípios específicos como a prioridade absoluta, a proteção integral e a condição peculiar de pessoa em desenvolvimento. Em estudo sobre o conteúdo jurídico do princípio da igualdade, Mello assinala que:

Esclarecendo melhor: tem-se que investigar, de um lado, aquilo que é adotado como critério discriminatório; de outro lado, cumpre verificar se há justificativa racional, isto é, fundamento lógico, para, à vista do traço desigualador acolhido, atribuir o específico tratamento jurídico construído em função da desigualdade proclamada. Finalmente, impende analisar se a correlação ou fundamento racional abstratamente existente é, in concreto, afinado com os valores prestigiados no sistema normativo constitucional. A dizer: se guarda ou não harmonia com eles ${ }^{40}$.

Caso a Proposta de Emenda Constitucional n. 171/93 venha a ser aprovada pelo Senado Federal e sancionada pelo Presidente da República, caberá ao Poder Judiciário, em sede de controle de constitucionalidade, impor a supremacia da Constituição ante a deliberação majoritária de ocasião que, além de reduzir direitos fundamentais, aproxima-se de uma doutrina penal utilitarista e com ideologia de defesa social.

No mesmo sentido, em atenção aos princípios da culpabilidade, da proteção integral e da condição peculiar de pessoa em desenvolvimento, Sposato defende que a sanção aplicada ao adolescente que comete ato infracional não deve ser a mesma aplicada a um adulto, mas sim deve ser observar a isonomia e a proporcionalidade, litteris:

Adultos, crianças e adolescentes, sendo pessoas diferentes entre si, não podem ser tratadas de igual maneira pelo Direito. Deve-se obedecer à isonomia e à proporcionalidade, respeitando-se o Princípio da Culpabilidade, da Proteção Integral e, principalmente, da condição Peculiar de Pessoa em Desenvolvimento. Dessa maneira, diante do cometimento do delito por menor de idade, busca-se como resposta não a defesa da impunidade ou a indiferença penal, mas a

\footnotetext{
${ }^{39}$ BRASIL. Constituição da República Federativa do Brasil de 1988. Brasília: Senado Federal, 1988. In: Diário Oficial da República Federativa do Brasil, Brasília, DF, 5 out. 1988. Disponível em:

<http://www.planalto.gov.br/ccivil_03/Constituicao/Constituiçao.htm>. Acesso em: 25 set. 2015.

${ }^{40}$ MELLO, Celso Antônio Bandeira de. 0 conteúdo jurídico do princípio da igualdade. 3. ed. 20. tir. São Paulo: Malheiros, 2011, p. 21-22.
} 
A REDUÇÃO DA MAIORIDADE PENAL E A VIOLAČ̃̃O AO PRINCÍPIO DA IGUALDADE: A CONDIÇÃO PECULIAR DE PESSOA EM DESENVOLVIMENTO COMO ELEMENTO CONSTITUTIVO DA IDENTIDADE DO ADOLESCENTE

compatibilidade da sanção em relação ao agente que o cometeu, inclusive por imperativo de ordem político-criminal ${ }^{41}$.

A redução da maioridade penal para a faixa etária dos 16 (dezesseis) anos, publicamente sem respaldo científico, considerando o desencontro de dados estatísticos veiculados na imprensa e em órgãos públicos, não observa as funções da pena no moderno processo penal de garantias por subsidiar um sentimento elitista de vingança contra uma minoria determinada, bem assim afronta o princípio da igualdade, sobretudo porque a deliberação majoritária atinge núcleo essencial da Constituição - a identidade do adolescente como corolário do princípio da dignidade da pessoa humana.

\section{CONCLUSÃO}

De acordo com a temática apresentada neste estudo, podem ser listadas as seguintes conclusões:

1. A legitimação para a supressão de direitos fundamentais de adolescentes com a redução da maioridade penal se fundamenta, basicamente, em uma questionável ideologia de defesa social e de seletividade;

2. Em contrariedade aos direitos e garantias fundamentais conquistados no decorrer da história, a Proposta de Emenda à Constituição n. 171/93 é muito mais um desejo elitista de vingança - ainda que veiculado pela mídia e assimilado irreflexivamente pela população - do que propriamente uma solução eficiente para a criminalidade, cenário que releva o desvirtuamento das funções da pena;

3. Diferenças, sejam naturais ou culturais, são os traços específicos das pessoas, que as tornam individualizadas e titulares de direitos fundamentais, razão pela qual concorrem para a formação da identidade da pessoa;

4. A construção da identidade do adolescente - ser humano em estágio de formação é apenas o ponto de partida para o desenvolvimento de uma sociedade plural e democrática em que as diferenças não são causa de exclusão, mas sim, de inclusão cidadã;

${ }^{41}$ SPOSATO, Karyna Batista. Direito Penal de Adolescentes: elementos para uma teoria garantista. São Paulo: Saraiva, 2013, p. 141. 
A REDUÇ̃̃O DA MAIORIDADE PENAL E A VIOLAČ̃̃ AO PRINCÍPIO DA IGUALDADE: A CONDICCÃO PECULIAR DE PESSOA EM DESENVOLVIMENTO COMO ELEMENTO CONSTITUTIVO DA IDENTIDADE DO ADOLESCENTE

LUCAS GONÇALVES DA SILVA MARCELO SERRANO SOUZA

5. No âmbito de um Estado Democrático de Direito, nenhuma maioria pode decidir em matéria de direitos fundamentais pelos demais indivíduos, sobretudo quando a minoria tem interesses ligados à sua identidade;

6. A Proposta de Emenda à Constituição n. 171/93 não apresenta uma solução concreta e comprovada empiricamente para reduzir a quantidade de atos infracionais protagonizada por adolescentes, mas pode servir como mais um instrumento altamente seletivo em relação a grupos que já se encontram em situação de vulnerabilidade social;

7. Em relação aos resultados da pesquisa por dados estatísticos fornecidos por instituições e órgãos oficiais, verificou-se que, além de o Brasil seguir a tendência mundial para a idade penal aos 18 (dezoito) anos de idade, a participação relativamente mínima de adolescentes em atos contra a vida não justifica a redução da maioridade penal para fins de política criminal do Estado brasileiro;

8. A redução da maioridade penal para a faixa etária dos 16 (dezesseis) anos configura hipótese de violação a um conteúdo material da constituição - o princípio da igualdade por não considerar a condição peculiar de pessoa em desenvolvimento como elemento de identidade do adolescente.

\section{REFERÊNCIAS}

ALVES, Cândida et al . Adolescência e maioridade penal: reflexões a partir da psicologia e do direito. Psicol. Polít., São Paulo , v. 9, n. 17, p. 67-83, jun. 2009 . Disponível em <http: / / pepsic.bvsalud.org/scielo.php?script=sci_arttext\&pid=S1519-

549X2009000100005\&lng=pt\&nrm=iso>. Acesso em: 18 ago. 2016.

ARAÚJO, Luiz Alberto David; NUNES JUNIOR, Vidal Serrano. Curso de Direito Constitucional. 14. ed. São Paulo: Saraiva, 2010.

BARATTA, Alessandro. Criminologia crítica e crítica do direito penal: introdução à sociologia do direito penal. Rio de Janeiro: Revan; ICC, 2002.

BARBOSA, Ana Christina Moreno Maia; COSTA, Ana Cristina Rodrigues da. Políticas de Atenção Integral - redes locais de atenção à criança e ao adolescente. In: AZEREDO, Beatriz; DUNCAN, Pedro Gomes (Orgs.). A experiência da área de desenvolvimento social no período 19962002. Rio de Janeiro: BNDES, 2002, p. 107-116.

BARROSO, Luís Roberto. Curso de Direito Constitucional Contemporâneo: os conceitos fundamentais e a construção do novo modelo. 5. ed. São Paulo: Saraiva, 2015. 


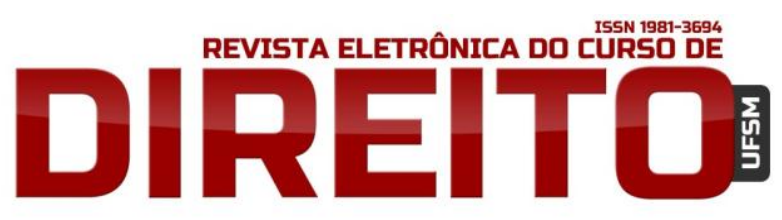

A REDUÇÃO DA MAIORIDADE PENAL E A VIOLAÇ̃̃O AO PRINCÍPIO DA IGUALDADE: A CONDIÇÃO PECULIAR DE PESSOA EM DESENVOLVIMENTO COMO ELEMENTO CONSTITUTIVO DA IDENTIDADE DO ADOLESCENTE

BINENBOJM, Gustavo. A nova jurisdição constitucional brasileira: legitimidade democrática e instrumentos de realização. 2. ed. Rio de Janeiro: Forense, 2004, p. 246.

BRASIL. Câmara dos Deputados. Disponível em:

<http: / /www2.camara.leg.br/camaranoticias/noticias/DIREITO-E-JUSTICA/494248-CAMARAAPROVA-EM-2-TURNO-REDUCAO-DA-MAIORIDADE-PENAL-EM-CRIMES-GRAVES.html>. Acesso em: 27 set. 2015.

Constituição da República Federativa do Brasil de 1988. Brasília. Diário Oficial da República Federativa do Brasil, Brasília: 5 out. 1988. Disponível em:

<http://www.planalto.gov.br/ccivil_03/Constituicao/Constituiçao.htm>. Acesso em: 25 set. 2015.

. Lei $\mathrm{n}^{\circ} 8.069$ de 13 de julho de 1990. Dispõe sobre o Estatuto da Criança e do Adolescente e dá outras providências. Diário Oficial da República Federativa do Brasil, Brasília, DF, 16 jul. 1990. Disponível em: <http://www.planalto.gov.br/ccivil_03/Leis/L6938.htm>. Acesso em: 25 set. 2015.

. Ministério da Justiça. Portal Brasil. Disponível em:

<http://www.brasil.gov.br/cidadania-e-justica/2015/06/menores-cometem-0-9-dos-crimes-nobrasil>. Acesso em: 28 set. 2015.

. Ministério Público do Estado do Paraná. Idade Penal: tabela comparativa. Disponível em:<http://http://www.crianca.mppr.mp.br/modules/conteudo/conteudo.php?conteudo=323>. Acesso em: 18 ago. 2016.

Presidência da República. Secretaria Especial dos Direitos Humanos. Conselho Nacional dos Direitos da Criança e do Adolescente. Sistema Nacional De Atendimento Socioeducativo SINASE/Secretaria Especial dos Direitos Humanos. Brasília - DF: CONANDA, 2006, p. 52. Disponível em: <http://www.conselhodacriança.al.gov.br/sala-deimprensa/publicacoes/sinase.pdf>. Acesso em: 25 set. 2015.

. Supremo Tribunal Federal. Habeas Corpus n. 85.687/RS, Rel. Min. Carlos Velloso, Segunda Turma, julgado em 17.05.2005. In: Site do Supremo Tribunal Federal. Disponível em: <http: / /redir.stf.jus.br/paginadorpub/paginador.jsp?docTP=AC\&docID=354246>. Acesso em: 28 set. 2015.

. Supremo Tribunal Federal. Recurso Extraordinário 845.779 RG, Rel. Min. ROBERTO BARROSO, julgado em 13.11.2014, PROCESSO ELETRÔNICO DJe-045 DIVULG 09-03-2015 PUBLIC 10-03-2015. In: Site do Supremo Tribunal Federal. Disponível em:

<http://www.stf.jus.br/portal/jurisprudencia/listarJurisprudencia.asp?s1=\%28direito+fundamen tal+identidade\%29\&base=baseRepercussao\&url=http://tinyurl.com/ovwgc5h>. Acesso em 28 set. 2015.

. UNICEF. UNICEF é contra a redução da maioridade penal. Disponível em: <http://http://www.unicef.org/brazil/pt/media_29163.htm>. Acesso em: 18 ago. 2016.

FERRAJOLI, Luigi. Derechos y garantias: la ley del más débil. Madrid: Editorial Trotta, 2001. 


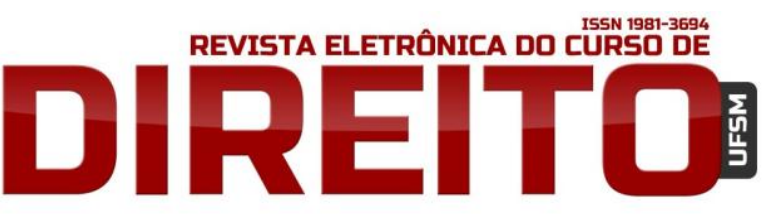

A REDUÇÃO DA MAIORIDADE PENAL E A VIOLAÇ̃̃O AO PRINCÍPIO DA IGUALDADE: A CONDIÇÃO PECULIAR DE PESSOA EM DESENVOLVIMENTO COMO ELEMENTO CONSTITUTIVO DA IDENTIDADE DO ADOLESCENTE

2002.

. Direito e Razão: teoria do garantismo penal. São Paulo: Editora Revista dos Tribunais,

FOUCAULT, Michel. Vigiar e punir: nascimento da prisão. 39 ed. Rio de Janeiro: Editora Vozes, 2011.

LOPES JR, Aury. Direito Processual Penal. 9. ed. rev. e atual. São Paulo: Saraiva, 2012.

MARTINAZZO, Celso José. Identidade Humana. Revista Contexto \& Educação. Ano 25, n. 84, jul/dez 2010, p. 35.

MELLO, Celso Antônio Bandeira de. 0 conteúdo jurídico do princípio da igualdade. 3. ed. 20. tir. São Paulo: Malheiros, 2011.

MENDES, Gilmar Ferreira. COELHO, Inocêncio Mártires. BRANCO, Paulo Gustavo Gonet. Curso de direito constitucional. 3. ed. rev. atual. São Paulo: Saraiva, 2008, p. 218.

MIR PUIG, Santiago. Introduccion a las Bases del Derecho Penal. Buenos Aires: BdeF, 2003.

MUÑOZ CONDE, Francisco. Direito penal e controle social. Rio de Janeiro: Forense, 2005.

RAMIDOFF, Mário Luiz. Lições de Direito da Criança e do Adolescente: ato infracional e medidas socioeducativas. Curitiba: Juruá, 2011.

ROXIN, Claus. Estudos de Direito Penal. 2. ed. Tradução de Luís Greco. Rio de Janeiro: Renovar, 2008.

SARLET. Ingo Wolfgang. A Eficácia dos Direitos Fundamentais: uma teoria geral dos direitos fundamentais na perspectiva constitucional. 12. ed. rev. atual. e ampl. Porto Alegre: Livraria do Advogado, 2015.

SILVA, José Afonso da. Curso de direito constitucional positivo. 34. ed. São Paulo: Malheiros, 2011.

. Poder Constituinte e Poder Popular. 1. ed. 3. tir. São Paulo: Malheiros, 2007.

SPOSATO, Karyna Batista. Direito Penal de Adolescentes: elementos para uma teoria garantista. São Paulo: Saraiva, 2013.

ZAFFARONI, Eugenio Raúl. O inimigo no direito penal. Tradução de Sérgio Lamarão. 3. ed. Rio de Janeiro: Revan, 2007.

Recebido em: 01/10/2015 / Revisões requeridas em: 16/08/2016 / Aprovado em: 31/08/2016 